\title{
Automatic Temperature Control System on Smart Poultry Farm Using PID Method
}

\author{
I Ketut Agung Enriko ${ }^{1,2 *}$, Ryan Anugrah Putra ${ }^{3}$, Estananto ${ }^{3}$ \\ ${ }^{1}$ Institut Teknologi Telkom, Purwokerto 53147, Indonesia \\ ${ }^{2} \mathrm{PT}$. Telkom Indonesia, Bandung 40152, Indonesia \\ ${ }^{3}$ School of Electrical Engineering, Telkom University, Bandung 40257, Indonesia \\ "Correspondence: agungenr@gmail.com
}

SUBMITTED: 28 October 2021; REVISED: 26 November 2021; ACCEPTED: 28 November 2021

\begin{abstract}
Chicken farmers in Indonesia are facing a problem as a result of the country's harsh weather conditions. Poultry species are very susceptible to temperature and humidity fluctuations. As a result, an intelligent poultry farm is necessary to intelligently adjust the temperature in the chicken coop. A smart poultry farm is a concept in which farmers may automatically manage the temperature in the chicken coop, thereby improving the livestock's quality of life. The purpose of this research is to develop a chicken coop prototype that focuses on temperature control systems on smart poultry farms via the PID control approach. The PID control method is expected to allow the temperature control system to adapt to the temperature within the cage, thereby assisting chicken farmers in their task. The sensor utilized is a DHT22 sensor with a calibration accuracy of 96.88 percent. The PID response was found to be satisfactory for the system with $K_{p}=10, K_{i}=0$, and $K_{D}=0.1$, and the time necessary for the system to reach the specified temperature was 121 seconds with a $1.03 \%$ inaccuracy.
\end{abstract}

KEYWORDS: Smart poultry farm, temperature sensor, PID control

\section{Introduction}

Indonesia's poultry business has a sizable market. Indonesian broiler meat output increased by 779,108 tons between 2005 and 2012, reaching 1,085,589 tons. This is an annual gain of 9.06 percent. Broiler meat production reached 1,689,584 tons in 2016. Additionally, Indonesia's egg output climbed from 681,147 tons in 2005 to $1,059,266$ tons in 2010 . This is an annual gain of nearly 6.80 percent. Egg production totaled 1,428,195 tons in 2016 [1]. Due to the harsh weather conditions [2-4], chicken growers face certain difficulties in keeping a comfortable habitat for their birds. Poultry species are quite sensitive to environmental temperature fluctuations. Chickens' body temperatures must be kept between $39.9^{\circ} \mathrm{C}$ and $41^{\circ} \mathrm{C}$ [4]. Chickens will perish if their body temperature rises by more than four degrees Celsius [5]. Due to the fluctuating severe temperatures, birds raised in the tropics are extremely susceptible to heat stress.

Heat stress occurs when cattle is subjected to high temperature increases both outdoors and inside [6,7]. As a result, we require a system capable of controlling the temperature in the chicken coop. A temperature control system for the chicken coop is required. Several more publications [8, 9] make use of the Proportional-Integral-Derivative (PID) Method. However, 
a simple implementation of PID is still required for practicality and simplicity. Smart poultry farms are a new way for chicken farmers to expand their livestock operations through the use of Internet of Things (IoT) technology in its current form. Due to the improved system responsiveness caused by feedback, this strategy is projected to aid farmers in improving the quality and production of their crops. The application of smart poultry is gaining traction in Indonesia, where hundreds of thousands of poultry exist.

\section{Literature Review}

\subsection{Broiler Chicken}

Broiler chicken or broiler is a type of chicken that grows very fast, and its meat is used to meet people's daily needs. Broiler chickens in Indonesia can be harvested within 5-6 weeks with a weight of $1.3-1.6 \mathrm{~kg}$, which is correctly raised to get optimal meat [10].

\subsection{Heat Stress}

Heat stress is a condition in which livestock find it challenging to balance heat production and body temperature expenditure. If the chicken experiences heat that exceeds its heat production (maximum heat losses), this can cause death in the chicken. Therefore, the chicken's body temperature should be maintained at around $39.9^{\circ} \mathrm{C}$ to $41{ }^{\circ} \mathrm{C}$. Chickens will die if their body temperature increases by $4^{\circ} \mathrm{C}$ or more [5]. To maintain body temperature, three-week-old broilers should be kept in an environment with temperatures ranging from $20^{\circ} \mathrm{C}$ to $25^{\circ} \mathrm{C}$ and a relative humidity of around $50 \%-70 \%[11], 26^{\circ} \mathrm{C}$ to $27^{\circ} \mathrm{C}$ for adult broilers, and laying hens between $18^{\circ} \mathrm{C}$ and $23.9^{\circ} \mathrm{C}$ [12]. Meanwhile, one-week-old chickens have a temperature of $32^{\circ} \mathrm{C}-34^{\circ} \mathrm{C}$ and two-week-old chickens have a temperature of $28^{\circ} \mathrm{C}-32^{\circ} \mathrm{C}$ [13].

\subsection{PID Control}

A PID controller determines the precision of a system with feedback as to its characteristics. PID control uses elements of P, I, and D values, which are mathematical models with Gain + Integral + Derivative as an input. The PID control component consists of three types, namely proportional, integral, and derivative. All three can be used together or separately depending on our desired response to the tool [14]. The PID algorithm is described in Figure 1.

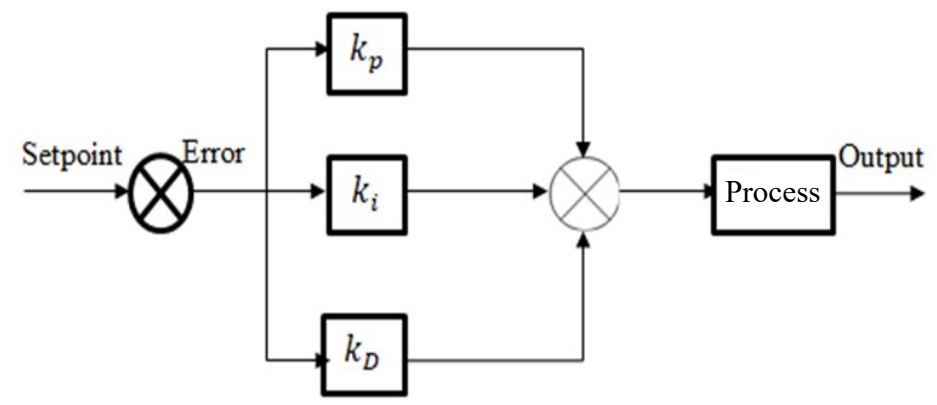

Figure 1. PID control system.

The equation of PID controller is given by

$$
u(t)=K_{p} e(t)+K_{i} \frac{1}{T_{i}} \int_{0}^{t} e(\tau) d \tau+K_{D} \frac{d e(t)}{d t}
$$


where the values are: $u(t)=$ control output; $e(t)=$ difference between set point and output, $K_{p}$ = gain Proportional; $K_{i}=$ gain Integral; $K_{D}=$ gain Derivative; $T_{i}=$ Integral time.

\subsubsection{Control P}

Proportional control (control P) is proportional to the error value. If the error value is significant, the greater the control signal generated by the controller. Proportional control influences the system [14], including:

a) Add or reduce stability.

b) Can improve transient response in particular: rise time and settling time.

c) Reduce (not eliminate) steady-state error.

$$
u(t)=K_{p} e(t)
$$

\subsubsection{Control I}

Integral control (control I) is proportional to the change in error. The greater the error value, the faster the control signal increases/changes, Integral control influences the system

[14] including:

a) Eliminate steady-state errors.

b) Slower response (compared to Proportional control).

c) Can increase instability.

$$
u(t)=K_{i} \frac{1}{T_{i}} \int_{0}^{t} e(\tau) d \tau
$$

\subsubsection{Control D}

Derivative control (control D) is proportional to the change in error. The faster the error changes, the greater the control action caused. Derivative control influences the system [14], including:

a) Provides a damping effect on the oscillating system to increase the value of $K_{p}$.

b) Improved transient response because it provides action when an error changes.

c) Only changes when there is an error change. D does not act when there is a static error, so D should not be used alone.

$$
u(t)=K_{D} \frac{d e(t)}{d t}
$$

\section{Design}

In this research, the authors want to create a system that can automatically monitor the chicken coop's temperature and move the fan. A temperature sensor in the form of a DHT22 sensor is needed. In Figure 2, it can be seen that the system design consists of sensors, controllers, serial monitors, motor drivers, and outputs. The sensor is used to detect the temperature in the chicken coop. The controller functions as the system's core, namely to process data from the sensor and 
produce output to drive the fan. The serial monitor serves to display the results of system work in real-time. Finally, the motor driver drives the fan according to the input given when the program is run. In this system, the desired error tolerance is $2 \%$.

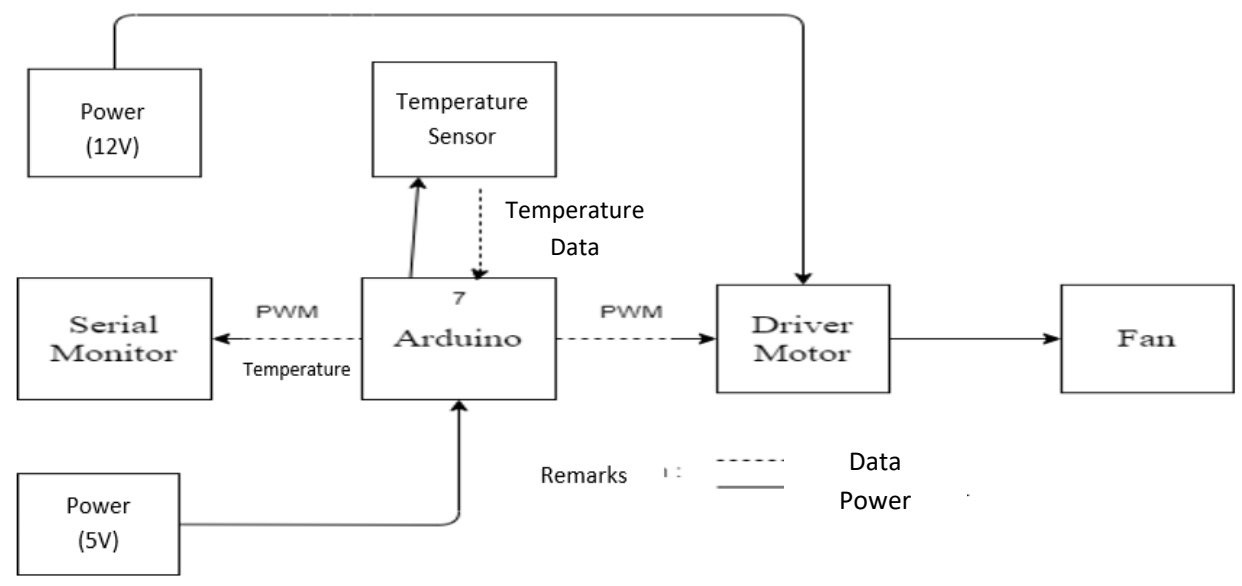

Figure 2. System block diagram.

Figure 3 is the flow of the programming algorithm. At the input stage, the temperature value for the setpoint is obtained from the existing temperature data. Then the temperature sensor reads the temperature value in the cage to see how much it differs from the setpoint, and then the PID method works to determine the fan speed to reach the set point.
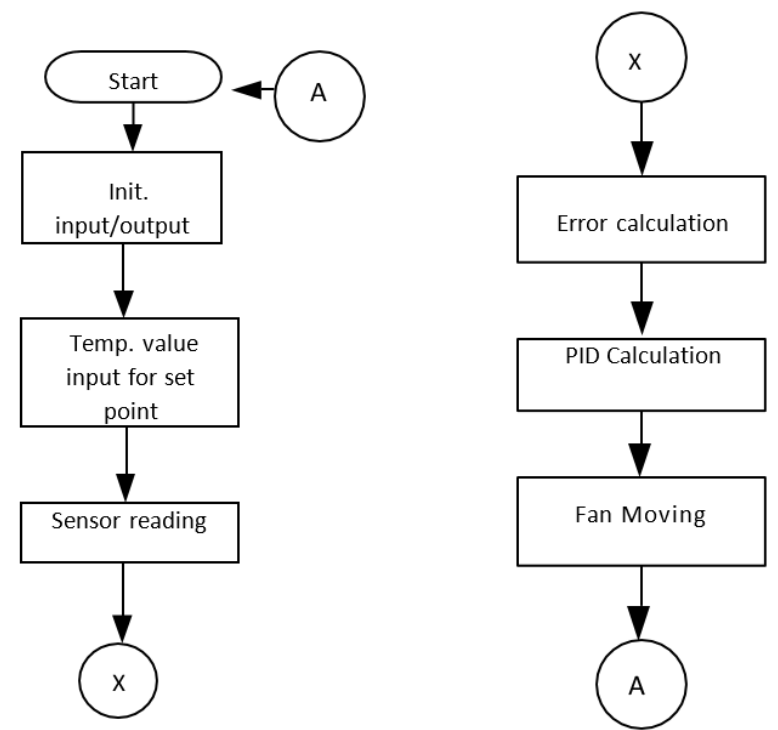

Figure 3. Programming algorithm flowchart.

\section{Results and Discussion}

\subsection{DHT22 Sensor Calibration and Accuracy Test}

The DHT22 sensor is used to detect the temperature value in the system. Tests are carried out to determine whether the DHT22 value follows the predetermined values and functions. The sensor value will be compared with the digital thermometer value. 


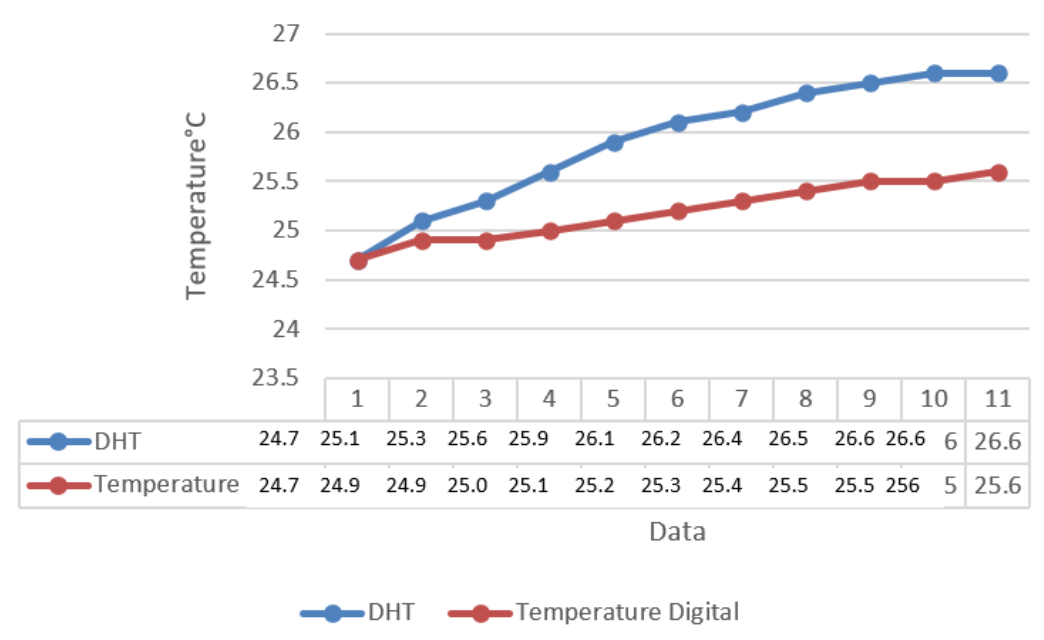

Figure 4. Comparison of temperature test results.

Table 1. System time and success test.

\begin{tabular}{cccll}
\hline $\begin{array}{c}\text { Chick age } \\
\text { (days) }\end{array}$ & $\begin{array}{c}\text { Setpoint } \\
\left(\text { temp }^{\circ} \mathbf{C}\right)\end{array}$ & $\begin{array}{c}\text { Time to reach } \\
\text { set point }\end{array}$ & Error & \multicolumn{1}{c}{ Remarks } \\
\hline $12-16$ & 29 & $121 \mathrm{~s}$ & $1,03 \%$ & \\
$17-20$ & 28 & $404 \mathrm{~s}$ & $0 \%$ & \\
$21-25$ & 27 & & & Minimum temp \\
$26-30$ & 25 & & & should reach \\
$31-35$ & 24 & & & $27.9^{\circ} \mathrm{C}$ \\
\hline
\end{tabular}

As illustrated in Figure 4 and Table 1, the DHT22 sensor and a digital thermometer with a 96.88 percent accuracy value were compared. As a result, the DHT22 sensor is appropriate for this application.

\subsection{PID Response Testing on The System}

The addition of a PID controller improves the system's responsiveness. PID is used to accelerate the rising time, the settling time, and to correct steady-state faults. When the PID is included, the response becomes more accurate by lowering the error value. The controller fixed the fault until it reaches the predetermined point.

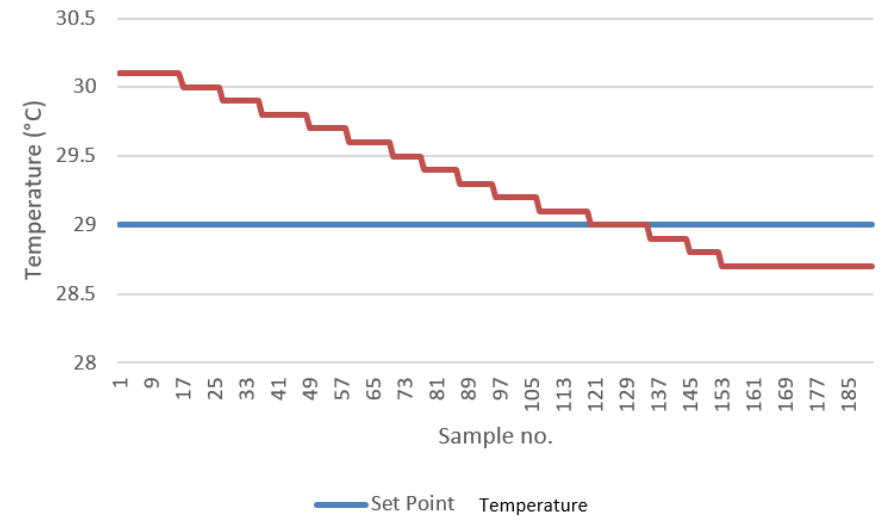

Figure 5. PID response on the system.

When $K_{p}=10, K_{i}=0$, and $K_{D}=0,1$, the system reaches the rise time on the 121st data and the settling time on the 153rd data with a 1.03 percent steady-state error. By examining the stability 
of the system using the authors' values for $K_{p}, K_{i}$, and $K_{D}$, we can see that the system response has a small error value and a rapid rising time. As a result, $K_{p}=10, K_{i}=0$, and $K_{D}=0.1$ are reasonable values due to the system's good reaction.

\subsection{System Time and Success Test}

This test is used to determine the system's success rate and the time required for the tool to reach the predetermined set point. The system was successful in this test when the setpoint was $29^{\circ} \mathrm{C}$ with a 1.03 percent error and when the setpoint was $28^{\circ} \mathrm{C}$ with a $0 \%$ error. When the setpoint temperature is set to $27^{\circ} \mathrm{C}, 25^{\circ} \mathrm{C}$, or $24^{\circ} \mathrm{C}$, the system is unable to reach the setpoint and can only reduce the temperature to $27.9^{\circ} \mathrm{C}$. When a setpoint temperature of $29^{\circ} \mathrm{C}$ is applied, the system takes 121 seconds to achieve the setpoint and remains steady for 23 seconds. Meanwhile, when the setpoint temperature is $28^{\circ} \mathrm{C}$, the system stabilizes after 404 seconds of reaching the setpoint (Fig 6).
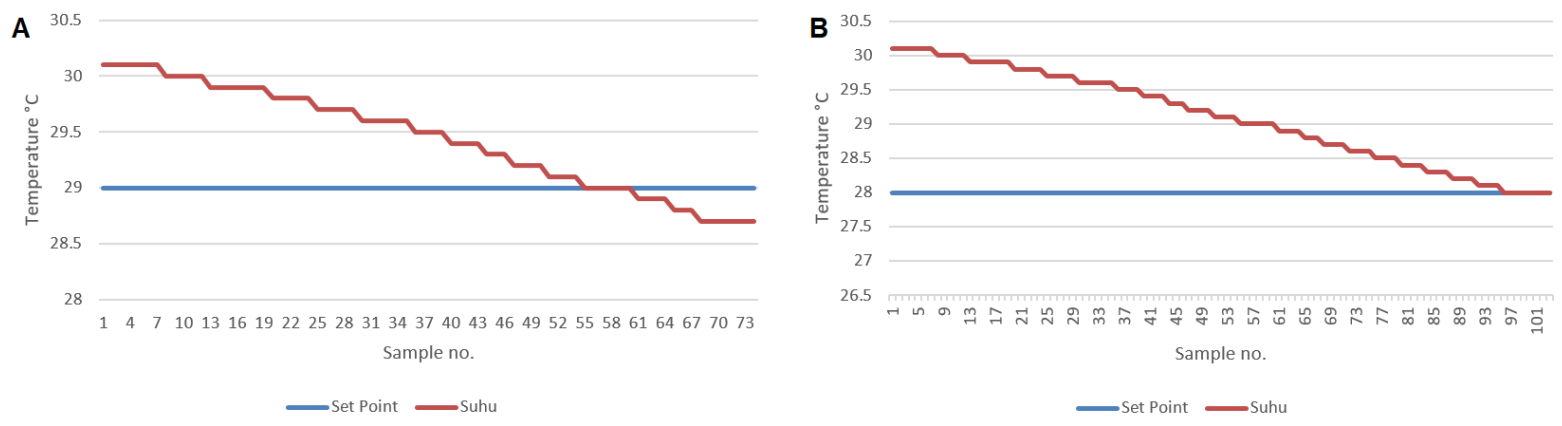

Figure 6. System response when set point is $29^{\circ} \mathrm{C}$ (A) and when set point is $28^{\circ} \mathrm{C}(\mathrm{B})$

\section{Conclusion}

Based on the results of testing and analysis of the temperature monitoring system in chicken coops using the PID method, it can be determined that the calibration of the DHT22 sensor has a sensor accuracy value of 96.88 percent, indicating that the DHT22 sensor is suitable for use in this system. $K_{p}=10, K_{i}=0$, and $K_{D}=0.1$ were used in trial and error to determine the optimal $K_{p}, K_{i}$, and $K_{D}$ values for the system to achieve the setpoint rapidly and with little errors. The system reaches the set point in 121 seconds, remains stable for 23 seconds, and has a 1.03 percent inaccuracy with these parameters.

\section{Competing Interest}

The authors declare no financial or non-financial competing interests.

\section{References}

[1] Saptana, S.; Fadhil, R.; Perwita, A.D. (2020). Sustainable Development Strategy On Poultry Industry In Indonesia. Jurnal Hukum Ekonomi Syariah 3, 1-25. http://dx.doi.org/10.30595/jhes.v0i0.6969.

[2] Osti, R.; Bhattarai, D; Zhou, D. (2017). Climatic Variation: Effects on Stress Levels, Feed Intake, and Bodyweight of Broilers. Revista Brasileira de Ciência Avícoladoi, 19, 489496. https://doi.org/10.1590/1806-9061-2017-0494 
[3] Lara, L.J.; Rostagno, M.H. (2013). Impact of Heat Stress on Poultry Production. Animals 3, :356369. https://doi.org/10.3390/ani3020356.

[4] Nayak, G.D.; Behura, N.C.; Sardar, K.K.; Mishra, P.K. (2015). Effect of climatic variables on production and reproduction traits of colored broiler breeder poultry. Veterinary World, 8, 472477. https://dx.doi.org/10.14202\%2Fvetworld.2015.472-477.

[5] Kutlu, H.R.; Forbes, J.M. (1993). Changes in growth and blood parameters in heat-stressed broiler chicks in response to dietary ascorbic acid. Livestock Production Science, 36, 335-350. https://doi.org/10.1016/0301-6226(93)90050-R.

[6] West, J.W. (2003). Effects of heat-stress on production in dairy cattle. Journal of Dairy Science, 86, 2131-2144. https://doi.org/10.3168/jds.S0022-0302(03)73803-X.

[7] Kale, V.S.; Rohit, D.K. (2016). Real Time Remote Temperature \& Humidity Monitoring Using Arduino and Xbee S2. International Journal of Innovative Research In Electrical, Electronics, Instrumentation And Control Engineering, 4, 175-179.

[8] Zou, C; Xu, Z; Yao, T; Xu, Z. (2015). Design of the Large Time-Delay Temperature Control System for a Large-Scale Chicken Farm. International Conference on Chemical, Material, and Food Engineering (CMFE). https://doi.org/10.2991/cmfe-15.2015.168.

[9] Ilyas, L; Ahmed. E; Nacer, S. (2019). PID Controller of a MIMO system using Ant Colony Algorithm and its application to a poultry house system. 5th International Conference on Optimization and Applications (ICOA), 1-7. https://doi.org/10.1109/ICOA.2019.8727710.

[10] 35-Days Old Broiler Chickens. (Accessed on March, 19 2020) Available online: https://hobiternak.com/pengertian-ayam-broiler/.

[11] Borges, S.A.; Fischer da Silva, A.V.; Maiorka, A; Hooge, D.M.; Cummings, K.R. (2004). Effects of diet and cyclic daily heat streson electrolyte, nitrogen and water intake, excretion and retention by colostomized male broiler chickens. International Journal of Poultry Science, 3, 313-321. https://dx.doi.org/10.3923/ijps.2004.313.321.

[12] Czarick, I.I.I.M.; Fairchild, B.D. (2008). Poultry housing for hot climates. In Poultry Production Hot Climates; Daghir, N.J., Ed.; Cromwell Press: Trowbridge, UK. pp. 81-131.

[13] Karczmarz, V. (2014). Thermal comfort in young broiler chickens (Gallus gallus domesticus) inferred from metabolic. Thesis, Linkoping University, Sweden.

[14] Ogata, K. (2002). Modern Control Engineering. 5th ed.; Pearson; Prentice Hall: London, UK. 